\title{
Homosexual Identity Development in E.M. Forster's Maurice: How Characters accept their Homosexuality?
}

\author{
Bayu Prawita Putra, Budi Darma, Ali Mustofa
}

Postgraduate Program of English Education and Literature, Surabaya State University, Indonesia

\begin{abstract}
This research aims to elaborate on Maurice Hall's homosexual identity development in Maurice. It uses Richard R. Troidden's homosexual identity development model that describes how committed homosexuals recall the process of accepting homosexuality as their identity. This theory covers four stages; sensitization, identity confusion, identity assumption, and commitment. The analysis discovers that Maurice Hall experiences happiness and sorrow in his journey as he encounters two major characters, Clive Durham and Alec Scudder. Maurice Hall fully accepts his homosexuality once he meets Alec Scudder who encourages Maurice to be his lover. This paper concludes that Maurice Hall's homosexual identity development is mostly influenced by people surrounding him such as Clive Durham who makes Maurice depressed due to a sudden break-up and Alec Scudder who makes Maurice later fully accepts his homosexuality. However, the ending seems happy since Maurice finally finds his romantic partner but it implicitly tells that homosexuality was unacceptable at the time, therefore, Maurice Hall and Alec Scudder find a new place to live together.
\end{abstract}

Keywords-Homosexual identity development, heteronormativity, homosexuality, literature.

\section{INTRODUCTION}

Homosexuality has been assumed as unacceptable sexuality for many years and is treated differently by people who oppose the existence of homosexuality. Historically, The American Psychiatric Association categorized homosexuality in their list of mental disorders. (Association, 1952). Therefore, individuals who have a desire or romantic affection toward men wanted to get rid of their homosexuality by having a consultation or a treatment with health professionals. However, the consultation or treatment does not guarantee that they can be heterosexual men because human's psychological problem is somehow complicated. If it does not work, health professionals may suggest the homosexual clients admit their homosexuality and look for places that are less judgemental than their previous places. Some individuals may keep their sexuality hidden and continue their normal lives.

The struggle of being gay is also represented in literature, particularly gay-themed novels. Maurice (1971) tells Maurice Hall's struggle in accepting his homosexuality. The process itself is full of surprises because he later has experienced a major breakdown from his lover, Clive ISSN: 2456-7620
Durham. Maurice's settings are mostly in England and its nearby towns and the time is in the early 20th-century. Maurice Hall is a good looking and reputablestockbroker in his town. However, he is different from other grown-up men because he is gay and wants a romantic relationship with a same-sex peer.

Maurice is written by E.M. Forster, a prominent English novelist, and is published posthumously. Forster insisted not to publish Maurice when he was still alive because homosexuality was illegal at the time. In Maurice, there are 3 prominent characters; Maurice Hall as the main character, Clive Durham and Alec Scudder as major characters. These two major characters bring significant experiences toward Maurice Hall's life journey. Therefore, this paper analyzes Maurice Hall's process of accepting homosexuality and later breaks the barrier he has built since he was very young.

\section{LITERATURE REVIEW}

This subchapter is divided into two parts; the first part is the elaboration of theories used to support the analysis of Maurice Hall's homosexual identity development. The 
second part is the elaboration of previous studies conducted by literary researchers. They have the same issue related to homosexuality in Maurice and any gaythemed novels, in general.

The writer of this paper uses Richard R. Troiden's homosexual identity development theory (Troiden, 1988). It elaborates individuals' stages of accepting homosexuality as their identity. Troiden's theory has four stages; sensitization, identity confusion, identity assumption, and commitment. These stages may develop differently in some individuals because they have different understandings related to homosexuality.

The sensitization, the first stage, commonly occurs before puberty. At this stage, most young homosexuals do not see homosexuality as part of their lives. However, others may have homosexual experiences when they were young and later act as a basis to assume themselves as homosexuals. The emergence of feeling different compared to their friends may facilitate the young boys to develop homosexual identity when they are grown up. Some young boys may not interested in sports such as football or basketball and later make them feel different.

Identity confusion, the second stage, is considered the most challenging part for young adults because they are aware of any homosexual behavior compared to the sensitization stage. They start questioning whether their feelings may lead to homosexual behavior. Identity confusion violates their self-image that they are not involved in any homosexual experiences and later creates confusion and anxiety. Cass (1984) describes how identity confusion emerges in the early phase:

You are not sure who you are. You are confused about what sort of person you are and where your life is going. You ask yourself the questions "Who am I? " "Am I a homosexual? " "Am I a heterosexual?"

This excerpt shows that closeted homosexuals are trying to figure out what has been happening to them. The writer of this paper assumes that identity confusion is formed after they encounter or experience any homosexual experiences through media or with a real person. The feeling of being different is slowly getting intense, and they are confused about it.

In identity confusion, Troiden elaborates on five responses that homosexuals commonly do when they are confused about their sexuality. They are (1) denial. (2) repair, (3) avoidance, (4) redefinition, and (5) acceptance. Denial, the first response, means the closeted homosexuals try to deny feelings or actions that lead to the exposure of homosexuality. The second, repair means they try to ask ISSN: 2456-7620 health professionals to eliminate their homosexuality by having consultations or treatments.

The third, avoidance means they avoid any feelings or actions that lead to homosexuality. There are six forms of avoidance; (1) limit feelings toward same-sex peers, (2) limit opposite-sex exposure to avoid discovery, (3) limit information about homosexuality, (4) conduct antihomosexual attitudes, (5) get involved in a heterosexual relationship as means of "cure", (6) escape homosexuality through drug use and abuse.

The fourth, redefinition means individuals try to reduce or tolerate identity confusion. They tend to assume that homosexuality is just a temporary phase and they may pass through it. There are four strategies of redefinition; (1) special case strategy, (2) ambisexual strategy, (3) temporary identity strategy, and (4) situational strategy.

The fifth, acceptance means closeted homosexuals admit that their feelings, behavior, or actions may lead to homosexuality and seem to explore more about it. For those who are aware of their homosexuality since they were young, acceptance reduces their anxiety and selfisolation, and may seek groups who support their homosexuality. Society and the environment may contribute to the formation of acceptance. However, negative prejudice toward homosexuals may postpone individuals' acceptance.

In the third stage, identity assumption is formed when homosexuals present their identity to other homosexuals. Closeted homosexuals may have regular encounters with other homosexuals and explore the gay culture. They develop a high tolerance for their homosexuality compared to the previous stages. Closeted homosexuals also think about telling his sexuality to non-homosexuals audiences that are called "coming out". However, the initial contacts with other homosexuals are important for those who are experiencing gay culture for the first time. The positive encounter may facilitate the process of coming out. In contrast, a negative impression of the first encounter may postpone their coming out and avoid seeing other homosexuals. Troiden states that gays commonly define themselves as sexually different in various ages, mostly from 19 to 21 years old (Troiden, 1988).

In the last stage, commitment means that individuals adopt homosexuality as a way of life. They are fully aware of their sexuality and see homosexuality as a valid identity. Some may commit a love relationship later, as Troiden states that a romantic relationship is one of the results of the commitment stage. Both partners are usually psychologically mature and are better to be financially independent, as well. Plummer (1975) adds that committed 
homosexuals do not try to become heterosexuals any longer because they see homosexuality is easier, less costly, and more attractive.

Besides Troiden's theory, the writer of this paper also employs queer theory to support the analysis. This theory focuses on the mismatches between sex, gender, and desire (Jagose, 1996). For years, homosexuals are reluctant to present their identity due to their fear of judgment that is addressed to them. Queer theory is beneficial due to its ability to analyze novels from a non-straight perspective. This means that the writer of this paper believes homosexuality is another human's sexuality along with other sexualities such as heterosexuality, bisexuality, and the like.

This study uses Lois Tyson's perspective, telling that an individual's sexuality is a fluid, fragmented, and dynamic collectivity of possible sexualities. Besides, it may vary at different points of his life (Tyson, 2006). This means that individuals may not have embedded into one sexual identity category because they have various experiences throughout their lives. Some factors contribute to individuals' sexuality, such as mass media, environment, or positive encounters with people. However, the heteronormative culture may postpone individuals' homosexual identity development because heterosexuality is seen as standard, acceptable sexuality, and is taken for granted. A love relationship and marriage are also suitable for heterosexuals, and this concept of heteronormative is respected and maintained in many cultures.

Besides the two theories above, the writer also uses previous studies or analysis conducted by literary researchers or theorists related to homosexuality in gaythemed novels. Lois Tyson (2006) discovers the doubt of Nick Carraway's sexuality in The Great Gatsby (1925). Nick shows some gay signs toward a male character in The Great Gatsby. He wants to get closer to McKee, a male character who has a feminine appearance. However, Nick's effort in approaching McKee is not much explored and acts as a minor scene.

Then, Bukowski (2008) examines the class position in E.M Forster's Maurice and A.T Fitzroy's Despised and Rejected. In Maurice, E.M. Forster, the novelist, shows the difficulties of the class system and its impact on selfacceptance as a gay and a love relationship. Losing the family's wealth and legacy are considered the risks of being gay and is well represented by Clive Durham, a major character in Maurice. Clive ends his relationship with Maurice and later is married to a woman to save his position in the family. Meanwhile, in Despised and Rejected, Dennis Blackwood has to wear a "mask" to hide his homosexuality. He comes from an upper-class family, and at the time he declined to join troops during World War I. This brings a question from his family and friends, but they do not associate his decision not to join with homosexuality due to his social status in society.

\section{METHOD}

The writer of this paper employs a context-oriented approach to literary criticism and uses Troiden's theory and queer theory to elaborate on Maurice Hall's homosexual identity development. Troiden's theory is elaborated into four stages; sensitization, identity confusion, identity assumption, and commitment. Queer theory is chosen to support the analysis related to Maurice Hall's homosexuality. In this paper, the primary data contains words, phrases, sentences, statements, dialogues as well as monologues collected from Maurice. The data are later be elaborated to identify the process of Maurice Hall's journey in accepting his identity.

\section{FINDINGS}

This subchapter presents the findings of Maurice Hall's homosexual identity development and his journey to accepting homosexuality. Sensitization, identity confusion, identity assumption, and acceptance are elaborated in the following paragraphs.

\section{Sensitization stage in Maurice}

This novel starts with Maurice's childhood in his last school day with Mr. Ducie, a stimulant teacher. In the first chapter, young Maurice is a not so remarkable fourteenyear-old. He has been invited by the teacher to listen to his talk about the love between man and woman. After several moments, young Maurice says, "I think I shall not marry" (Forster, 1971: 7). At the time, young Maurice was not aware of his saying as he immediately responded to $\mathrm{Mr}$. Ducie's topic. Maurice's saying can be considered as the feeling of being different as Troiden states in his theory. The feelings experienced in individuals' childhood can be a trigger to develop in their adulthood. His sudden response to the relationship between a man and a woman is considered immature because he is still young and might change his decision later. According to Troiden, sensitization is formed through an individual's childhood, young Maurice might see his parents did not get along very well, therefore, marriage is not his priority, and focuses on his paper and career when he is grown up. He has to support his family financially because his father is passed away and Maurice Hall only has a mother and two sisters. Related to homosexual identity development, 
young Maurice's homosexuality is not well developed because he does not link his decision not to marry with any homosexual behavior.

\section{Identity confusion stage in Maurice}

In this stage, closeted homosexuals are aware of the disruption of their previous image, heterosexuals. There are five responses related to identity confusion; (1) denial, (2) repair, (3) avoidance, (4) redefinition, and (5) acceptance. In Maurice, Maurice Hall denies his feelings due to his fear of being gay. Denial is the first response in the identity confusion stage. It can be seen in the following excerpt.

"Because I must be going", he was in no hurry, but his heart, which had never stopped beating quickly, impelled him to say this. (Forster, 1971: 21)

This excerpt shows that Maurice is aware of his homosexuality but he is afraid of showing it to Clive Durham, his new acquaintance. His heartbeat implicitly tells that Maurice has developed romantic feelings toward same-sex peers. Therefore, denial is commonly experienced by closeted homosexuals due to their fear of being known as gay.

As time goes by, Maurice Hall experiences a devastating moment with Clive Durham. Clive has decided to end the romantic relationship with Maurice because he wants to marry a woman. Consequently, Maurice gets depressed and visits doctor Lasker Jones to get a treatment to be back to what Maurice calls as a "normal" man.

He asked, "What's the name of my trouble? Has it one?"

"Congenital homosexuality."

"Congenital how much? Well, can anything be done?" "Oh, certainly, if you consent." (Forster, 1971: 114)

It can be seen that Maurice is experiencing repair as Troiden states in the theory. The repair is triggered when Maurice is in sorrow once he can not control himself due to a sudden break-up. Doctor Lasker Jones is a hypnotherapist and tells that the treatment is not always successful. Related to homosexual identity development, the repair only emerges when the closeted homosexuals feel the pain of their homosexual behavior. On the other contrary, closeted homosexuals who are happy about their homosexuality or romantic relationship may not think to "cure" their sexuality.

Then, avoidance also emerges when closeted homosexuals avoid or limit their homosexual desires. Maurice softly warns Clive Durham not to confess his romantic feelings as it is considered a crime in England.

“Durham, you're an Englishman. I'm another. Don't talk nonsense. I'm not offended, because I know you don't mean it, but it's the only subject absolutely beyond the limit as you know, it's the worst crime in the calendar, and you must never mention it again. (Forster, 1971:37)

This excerpt shows that Maurice is limiting his homosexuality though he has romantic feelings toward Clive. It implicitly delivers that homosexuality was a taboo thing in England at the time. Both Maurice and Clive are closeted homosexuals and should have been aware of the risks of being gay lovers in their society. Related to homosexual identity development, avoidance also commonly experience by closeted homosexuals who do not fully admit their homosexuality. As Troiden states, there are six forms of avoidance. However, in Maurice, Maurice Hall only experiences one response that is the limitation of homosexual behavior.

In redefinition, closeted homosexuals try to tolerate their homosexual behaviors by saying some conventional lines such as "I'm doing this only with you" or "this is just a temporary phase, I later pass this moment". In Maurice, Maurice Hall is spending a night with Alec Scudder, a servant of Durham's family. Both of them are not lovers and Maurice thinks the sexual relationship only lasts for a night.

They slept separately at first, as if proximity harassed them, but towards morning a movement began, and they woke deep in each other's arms. (Forster, 1971: 125)

This excerpt shows that Maurice Hall's homosexuality emerges once he meets another homosexual. Maurice seems happy spending a night with Alec Scudder and disregards his effort to eliminate his homosexuality at the time. Maurice's tolerance toward homosexuality has increased and may develop into acceptance once he fully admits his romantic feelings toward men.

The acceptance, the last response in identity confusion, emerges after closeted homosexuals much tolerate on their sexuality. In Maurice, Maurice Hall finally accepts his homosexuality after doctor Lasker Jones suggests Maurice to find countries that are less judgemental when it comes to homosexuality. It can be seen in the following excerpt.

"I'm afraid I can only advise you to live in some country that has adopted the Code Napoleon," he said. 
"I don't understand."

"France or Italy, for instance. There homosexuality is no longer criminal." (Forster, 1971: 135).

Maurice's acceptance of his homosexuality is strengthened by doctor Lasker Jones who has many homosexual clients. Maurice Hall's second treatment does not work for eliminating his homosexuality because he does not have any romantic feelings toward women. Therefore, Maurice is not surprised by the result because he has been in some situations who are involving other homosexuals such as Clive Durham and Alec Scudder. Doctor Jones' advice would be beneficial once Maurice fully admits his homosexuality and find a romantic partner to live outside England. Related to homosexual identity development, acceptance here means that Maurice Hall is fully aware of his homosexuality and may look for more information about it.

\section{Identity assumption stage in Maurice}

In this stage, individuals have established their homosexuality and shared it with other homosexuals. In Maurice, Maurice Hall and Clive Durham used to have their private time on Wednesdays or weekends.

But every Wednesday he slept at Clive's little flat in town. Weekends were also inviolable. (Forster, 1971: 64).

Maurice and Clive used to secretly dating and choose to escape from the crowd because they are gays. At the time, having a private place was considered the only option because it was riskier to show their identity publicly. Both Maurice and Clive come from upper-class society, therefore, some people are not brave enough to ask for more information about their private time. As Troiden states, homosexuals commonly define themselves as gay at different ages ranging from 19 to 21 years old. However, the writer of this paper assumes that some people may predict that both Maurice and Clive have an intense bond and may lead to homosexual behavior. Maurice and Clive are depicted as adult Englishmen who have their jobs in society. Maurice is a stockbroker and Cive is a politician. As time goes by, Maurice Hall later admits his homosexuality with his new partner, Alec Scudder, while Clive Durham has declined his homosexuality and later married to a woman.

With Alec Scudder, Maurice has shown his identity as seen in the following excerpt.

He snuggled closer, more awake than he pretended, warm, sinewy, happy. Happiness overwhelmed Maurice too. (Forster, 1971: 147)
Maurice is being happy sharing his homosexuality with Alec. In Maurice, Maurice Hall has met two people who contribute to his homosexuality. His former lover was Clive Durham and Alec Scudder is considered a single sexual encounter. As time goes by, Maurice has explored gay culture such as sharing their romantic desire and having private time. Therefore, his previous intention to eliminate his homosexuality was just a temporary excuse due to his inability to control emotion after a sudden break-up. Related to Maurice's homosexual identity development, his homosexuality has developed quite intense because of his encounters with other homosexuals.

\section{Commitment stage in Maurice}

This commitment is described as the last stage of individuals' homosexual identity development. They admit their homosexuality and present their identity to nonhomosexual audiences and later choose it as part of their lives. In Maurice, Maurice Hall and Alec Scudder are officially lovers and are ready to face the world.

"Yes, and that's why we've got to fight."

"Who wants to fight?" He sounded annoyed.

"There's bin enough fighting."

“All the world's against us. We've got to pull ourselves together and make plans, while we can." (Forster, 1971: 147)

Both of them are aware that England does not support homosexuals and later they need to find a new place to live together. However, the new place is not explored in the last chapter, but the writer of this paper predicts they will not move far from England because they are not financially independent at the time. Maurice Hall and Alec Scudder have sacrificed their jobs and decided to have a new start. Maurice may offer a happy ending since Maurice and Alec pursue their happiness as gays, but they have lost wealth and social status in places they live previously. They need to find new jobs to find a home and fulfill their daily needs. However, Maurice and Alec Scudder may not present their identity as gays since they find a new place without telling their families. Unfortunately, Maurice's mother and his sisters know nothing about Maurice's romantic relationship. Both Maurice and Alec should have told their identity as gays and there is a possibility that Maurice and Alec's families can tolerate their sexuality.

Though Maurice has seen his homosexuality as a valid identity, he is not ready to present his identity to his family, coworkers, and non-homosexual audiences. Though the society members are not much explored, some of them are the religious type of people. Therefore, he 
breaks the rules of being a well-known stockbroker who is previously assumed tobe a heterosexual and later escapes the world with Alec Scudder. In Maurice, commitment means they commit a romantic relationship with a person who is also a committed homosexual.

\section{DISCUSSION}

In Maurice, some characters like Mr. Ducie and Clive Durham maintain the heteronormative value and it affects to Maurice Hall's homosexual identity development. Firstly, young Maurice has been invited by Mr. Ducie to discuss the harmony of a heterosexual relationship. Mr. Ducie believes that the romantic relationship between a man and a woman brings harmony on this earth. Interestingly, he only tells this topic to young Maurice even though other schoolboys are the same age as young Maurice. The writer of this paper assumes that the stimulant teacher wants his student to follow what he believes about the heterosexual relationship. Besides, Mr. Ducie seems to use his authority as a stimulant teacher to implicitly tells his belief about the happiness of committing a romantic relationship with the opposite sex.

Clive Durham also believes that a long term relationship is only appropriate for heterosexuals, therefore, he ends his romantic relationship with Maurice Hall. Clive is depicted as a character who sees homosexuality has no future. Having a romantic relationship with Maurice does not bring any benefits, instead, Clive may lose his family legacy if his whole family knows he is gay. Therefore, for closeted homosexuals, there is a possibility of a sudden break-up due to the strong influence of heteronormativity.

Then, finding a love partner for homosexuals is slightly complicated compared to heterosexuals. Normally, both gay lovers secretly dating or wearing a "mask" to avoid any conflicts from people who oppose the existence of homosexuality. The writer of this paper assumes that these people are aware of their sexuality, at the same time, they can not present it to most people such as family, friends, or coworkers. In Maurice, no one knows about the romantic relationship between Maurice Hall and Clive Durham until they break up. It implicitly tells that not telling their love relationship to anyone was the only option at the time. This kind of relationship may last forever once both partners are committed homosexuals. Maurice Hall and Alec Scudder are depicted as committed homosexuals who are ready to face the world.

The absence of a mother's support is interesting to be analyzed. In Maurice, Mrs. Hall is a religious type of person and has a regular schedule for prayer in church. From her behavior, she may not tolerate Maurice's ISSN: 2456-7620 homosexuality and may feel annoyed with Alec Scudder if they present themselves as gay lovers. Consequently, Maurice decides not to tell about his romantic relationship and later finds a new place with Alec Scudder without saying any goodbyes to his family. The writer of this paper assumes that Maurice cares for his family and he may tell the truth shortly once Maurice has a settled job and life.

\section{CONCLUSION}

The results of this paper tell that Maurice Hall experiences happiness and sorrow in his homosexual identity development. It starts with the feeling of being different when he was being asked to respond to $\mathrm{Mr}$. Ducie's topic. Young Maurice prefers not to marry when he is grown up. Then, he experiences a devastating moment when Clive Durham, his ex-lover, wants to marry a woman. Here, repair emerges as he could not manage his anxiety with a sudden break-up. However, Maurice has been diagnosed with congenital homosexuality by the doctor Lasker Jones telling that no treatment is working to eliminate Maurice's homosexuality. As time goes by, Maurice is trying to accept his homosexuality, at the same time, he has been in a difficult situation when he meets Alec Scudder, a person who later to be Maurice's lover. Alec kind of demands Maurice to treat him fairly since Maurice comes from a reputable stockbroker while Alec is a servant from Durham's family. Maurice ends with the escape from this gay lover and starts a new life in a new place.

Therefore, this paper concludes that Maurice Hall's homosexual identity development is mostly influenced by people surrounding him such as Clive Durham who makes Maurice depressed due to a sudden break-up, and Alec Scudder who makes Maurice later fully accepts his homosexuality. However, the ending seems happy since Maurice finally finds his romantic partner but it implicitly tells that homosexuality was unacceptable at the time, therefore, Maurice Hall and Alec Scudder find a new place to live together.

\section{REFERENCES}

[1] Association, T. C. (1952). Diagnostic and Statistical Manual of Mental Disorders. Washington: American Psychiatric Association.

[2] Bukowski, J. (2008). Unseen Identity. (Unpublished Thesis). Vermont: The University of Vermont.

[3] Cass, V. (1984). Homosexual Identity Formation: Testing a Theoretical Model. The Journal of Sex Research, 143-167.

[4] Fitzgerald, F. S. (1925). The Great Gatsby. United States: Charles Scribner's Sons. 
[5] Forster, E. (1971). Maurice. United Kingdom: Hodder Arnold.

[6] Jagose, A. (1996). Queer Theory: An Introduction. New York: NYU Press.

[7] Maurice Summary \& Study Guide. (2020, September 7). Retrieved from http://www.bookrags.com/studyguidemaurice/\#gsc.tab=0

[8] Plummer, K. (1975). Sexual Stigma: An Interactionist Account. London: Routledge and Kegan Paul.

[9] Troiden, R. R. (1988). Homosexual Identity Development. Journal of Adolescent Health Care, 105-113.

[10] Tyson, L. (2006). Critical Theory Today: A User-Friendly Guide. New York: Routledge.

\section{APPENDIX}

\section{Synopsis of Maurice}

Maurice, a fourteen-year-old boy, is discussing the harmony of the love relationship between a man and a woman with Mr. Ducie, his prep-school teacher. It ends up with the promise that Maurice has to fulfill Mr. Ducie's invitation saying that he will be attending a dinner with his future wife.

Later, Maurice continues to study in Cambridge and meets Clive Durham. Shortly after, Maurice and Clive Durham develop strong bonds and become close friends. Clive recommends Maurice the Ancient Greeks book, which discusses homosexuality. When Maurice is enchanted with this book, Clive confesses his love for Maurice. Maurice is shocked by Clive's confession, then he softly avoids Clive.

Clive is heartbroken and asks Maurice not to see him again. Maurice feels depressed and later meets Clive to ask for an apology. However, Clive finally accepts Maurice's apology, and they hide their love relationship with anyone for three years.

Maurice is stressed out after having expelled from school due to the strict law of homosexuality. Then Maurice returns home and works in his father's old stockbroker firm. On the other hand, Clive finishes his study and becomes a lawyer. Even though they are separated, Maurice and Clive still be together and have their own private time on Wednesdays.

After several years, Clive has slightly changed his personality toward Maurice. It happens after he has recovered from severe flu. Clive assumes his illness has indeed eliminated his homosexual desire. After some time they have not met, Clive tells Maurice that they can become friends because he does not have any romantic or sexual feelings for Maurice. Maurice also gets surprised that Clive wants to get married to a lady.
Maurice desperately wants to eliminate his homosexuality by having a schedule with Lasker Jones, the hypnotherapist. However, after several attempts, doctor Jones suggests Maurice accepts his homosexuality and recommends some countries that are less harmful to homosexuals.

After some moments, Maurice is spending some days in Clive's house after Clive is married to a lady. Maurice and Clive are no longer as a lover but as a friend. In one night, Maurice meets Alec Scudder, one of Clive's employees. Maurice is embarrassed by his feelings and tries to avoid Alec. Alec is disappointed and heartbroken by Maurice's behavior and sends him letters that frighten Maurice. Alec does not want Maurice to treat him differently because he is a servant, and Maurice is a reputable stockbroker.

Maurice finally manages to meet Alec in London. Maurice realizes that he has fallen in love with Alec. Maurice makes a big decision by asking Alec to run away with him rather than emigrating to Argentina. At first, Alec does not accept Maurice's offer. Finally, Alec agrees to be Maurice's lover and both of them leave their current town and have a new start together.

The summary was taken from bookrags.com and modified by Bayu Prawita Putra. 